\title{
A randomized, double-blind, placebo-controlled trial of paracetamol and ketoprofren lysine salt for pain control in children with pharyngotonsillitis cared by family pediatricians
}

Nicolino Ruperto ${ }^{1 *}$, Luigi Carozzino², Roberto Jamone ${ }^{2}$, Federico Freschi ${ }^{2}$, Gianfranco Picollo ${ }^{2}$, Marcella Zera ${ }^{2}$, Ornella Della Casa Alberighi ${ }^{3}$, Enrica Salvatori ${ }^{4}$, Alessandra Del Vecchio ${ }^{4}$, Paolo Dionisio ${ }^{4}$ and Alberto Martini ${ }^{5}$

\begin{abstract}
Background: To evaluate the analgesic effect and tolerability of paracetamol syrup compared to placebo and ketoprofen lysine salt in children with pharyngotonsillitis cared by family pediatricians.

Methods: A double-blind, randomized, placebo-controlled trial of a $12 \mathrm{mg} / \mathrm{kg}$ single dose of paracetamol paralleled by open-label ketoprofren lysine salt sachet $40 \mathrm{mg}$. Six to 12 years old children with diagnosis of pharyngo-tonsillitis and a Children's Sore Throat Pain (CSTP) Thermometer score $>120 \mathrm{~mm}$ were enrolled. Primary endpoint was the Sum of Pain Intensity Differences (SPID) of the CSTP Intensity scale by the child.

Results: 97 children were equally randomized to paracetamol, placebo or ketoprofen. Paracetamol was significantly more effective than placebo in the SPID of children and parents $(P<0.05)$ but not in the SPID reported by investigators, 1 hour after drug administration. Global evaluation of efficacy showed a statistically significant advantage of paracetamol over placebo after 1 hour either for children, parents or investigators. Patients treated in open fashion with ketoprofen lysine salt, showed similar improvement in pain over time. All treatments were welltolerated.
\end{abstract}

Conclusions: A single oral dose of paracetamol or ketoprofen lysine salt are safe and effective analgesic treatments for children with sore throat in daily pediatric ambulatory care.

Keywords: paracetamol, ketoprofen lysine salt, placebo, randomized double blind clinical trial, family pediatricians

\section{Background}

Treatment of acute pain, particularly in pediatric population, should be a priority for clinicians. In the past, pain has been underestimated and sometimes undertreated in children, probably due to individual and social attitudes toward pain and the complexity of its assessment in children [1-3]. Nowadays, the importance of pain control in the pediatric population is widely recognized. However, there is still a lack of adequate clinical trials assessing the pharmacological effects of the oral analgesics commonly used in pediatric daily primary care $[3,4]$.

\footnotetext{
* Correspondence: nicolaruperto@ospedale-gaslini.ge.it

'IRCCS G Gaslini, Pediatria II, Reumatologia, PRINTO, Genoa, Italy Full list of author information is available at the end of the article
}

Paracetamol (acetaminophen) is currently one of the most popular and widely used analgesic and antipyretic in children for the symptomatic treatment of acute pain and fever. Differently from non-steroidal anti-inflammatory drugs (NSAIDs), paracetamol does not produce gastrointestinal damage or untoward cardio-renal effects. On the other hand, its anti-inflammatory activity is negligible [5].

Aim of this trial was to evaluate and confirm the analgesic effect and the tolerability of a paracetamol syrup formulation administered at the dosage of $12 \mathrm{mg} /$ $\mathrm{kg}$ in children with pharyngotonsillitis. The study was carried out in double-blind conditions in comparison to placebo and controlled, in an open fashion, with ketoprofen lysine salt $40 \mathrm{mg}$ as the positive control. 


\section{Methods}

\section{Study design}

The study design was a randomized, double-blind, parallel group, placebo-controlled trial of $12 \mathrm{mg} / \mathrm{kg}$ single dose paracetamol syrup with an open label comparison with ketoprofen lysine salt sachet $40 \mathrm{mg}$ as the positive control over three days.

\section{Study setting and population}

Between March 2006 and May 2007, the study was set in five pediatric primary care public ambulatories of the Italian national net of family pediatricians. The protocol was approved by the Ethics Committee and parents and children signed the approved informed consent form as appropriate.

Those eligible were 6-12 year-old with diagnosis of pharyngo-tonsillitis confirmed by a score $>5$ in the Tonsillo-Pharyngitis Scale (TPS) [6], a score $>120 \mathrm{~mm}$ in the Children's Sore Throat Pain (CSTP) Thermometer [6], and a maximum 1-week disease duration. Subjects were excluded from the study if they had positive history of hypersensitivity or allergy to the study medications, other conditions know to interfere with assigned drugs, or if they used any antipyretic drugs or throat lozenges in the past 6 hours, and/or analgesics or any "cold" medication in the past 8 hours.

\section{Study treatments}

After consent and baseline assessments, children were randomly assigned to 1 of the 3 groups (Figure 1). The first and second groups received a single administration of paracetamol syrup $12 \mathrm{mg} / \mathrm{kg}$ (Tachipirina ${ }^{\circledR}$ syrup $2.4 \%$, ACRAF SpA), corresponding to $1 \mathrm{~mL} / 2 \mathrm{~kg}$ of body weight or placebo syrup $(1 \mathrm{~mL} / 2 \mathrm{~kg}$ of body weight) in a double blind fashion. The third group was assigned, to open label to ketoprofen lysine salt $40 \mathrm{mg}$ $\left(\mathrm{Oki}^{\circledR} 80 \mathrm{mg}\right.$ granules for oral suspension, half sachet, Dompè $\mathrm{SpA}$ ) in order to have an indirect comparison

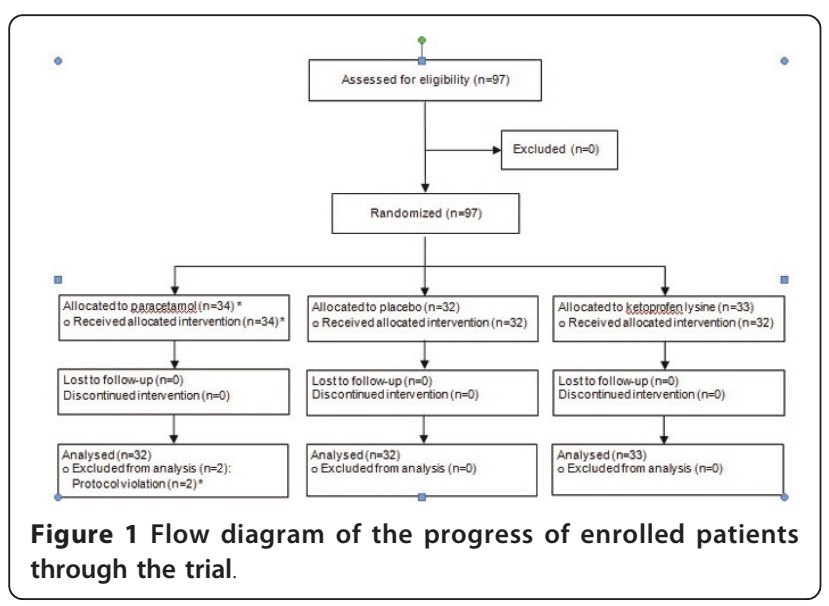

with a widely used analgesic in Italy. A double dummy design was not forecast for technical and logistical reasons. No further dosing was allowed in the following 4 hours. After the clinical assessments by the family pediatrician, patients assigned in a double blind fashion to the syrup (active or placebo) received a bottle of paracetamol for the home management of pain. The paracetamol dosage to be used was $12 \mathrm{mg} / \mathrm{kg}$ up to $4-5$ times daily, and ketoprofen $40 \mathrm{mg}$ (half $80 \mathrm{mg}$ sachet) every 8 hours for a maximum of 3 administrations daily. The paracetamol $12 \mathrm{mg} / \mathrm{kg}$ single dose was chosen on the basis of the therapeutic range of $10-15 \mathrm{mg} / \mathrm{kg}$ widely recognized as effective in the treatment of fever and pain control [7] while the ketoprofen lysine salt dosage was the same as recommended in its own Summary of Product Characteristics.

There was one randomization sequence computer generated via Microsoft Access 2000. A pre-assigned list with progressive numbering was provided to each investigator. The double-blind conditions were obtained using paracetamol matching placebo syrup, including matching external box and internal opaque bottle. Ketoprofen lysine salt was not masked due to manufacturing issues, and was provided in sachets as per the current Italian marketing authorization.

\section{Outcome measures}

Three assessments of pain intensity were performed at the primary care facilities (baseline, 30 minutes and 1 hour after treatment), and three at home (2, 3 and 4 hours after treatment). On day 4 children came back to their family pediatrician office for final visit assessment.

At baseline, the investigators assessed the patient's medical history, physical examination, concomitant treatments, and underwent a rapid antigen detection testing (Testpack Plus Strep-A OBC $\mathrm{II}^{\circledR}$, Abbott). In case of positive findings on the test, an appropriate antibiotic for the treatment of streptococcal infection was prescribed. The pediatrician evaluated the severity of tonsillo-pharyngitis by the TPS a 0-3 categorical scale (score range 0-21) considering 7 clinical parameters: body temperature, tonsils' volume, pharyngeal' colour, enanthema, size, number and sensibility of anterior cervical lymph node. Children completed the CSTP thermometer as proposed by Schachtel et al [6], a vertical paper drawn 0-200 $\mathrm{mm}$ thermometer with anchoring words no pain $(0 \mathrm{~mm})$ and very severe pain $(200 \mathrm{~mm})$, divided at $10 \mathrm{~mm}$ intervals; the child was asked to swallow and to "color in the pain thermometer so that it shows how much your throat hurts now" At all fixed times, the child was also asked to indicate pain intensity using the horizontal five-faces of the Children's Sore Throat Relief Scale (CSTRS) in the version proposed by Schachtel et al [6]; this scale consisted of a series of five 
faces, from "no relief" on the left to "complete relief" on the right.

Before assigning the treatment, pain intensity was also independently rated by the investigator and parent (usually the mother) using the Sore Throat Pain Intensity (STPI), a 0-100 mm VAS, with anchoring words no pain (child has no difficulty in deglutition at $0 \mathrm{~mm}$ ) and very severe pain (child has a lot of difficulties in deglutition at $100 \mathrm{~mm}$ ) [6].

Both the investigator and parent evaluated pain intensity at $30 \mathrm{~min}$ and 1 hour after dosing, by the STPI Scale, while the child used the CSTP Intensity Scale. Using the same scale, the child and the parent also assessed at home pain intensity at 2, 3, and 4 hours after treatment. At day 4 after treatment period, a final visit was performed by the family pediatrician in its office to re-evaluate the patient's clinical conditions.

Efficacy was also evaluated by parent and investigator on a 5 levels categorical scale (very good, good, fair, poor or very poor) and by children on a 3 levels categorical scale (a lot, little or none).

In addition 1 hour after treatment, and at the final visit, the investigator verified the occurrence of adverse events during the study period and judged tolerability using a 5-point scale (from very good to very poor). Tolerability was also assessed by the parent at 1 and 4 hours after treatment.

The use of the CSTP Thermometer, and of the CSTRS happy-sad faces for efficacy were explained by the family pediatrician to the child by using pre-printed color images for adequate training. Training was also offered to the parent for the use of the STPI and overall efficacy and tolerability categorical scales. Both the child and the parent completed their baseline pain assessment before randomization and drug assignment. All intervention including physical examination, additional medication assessment scale were prospectively documented on ad hoc designed 3 carbon copy paper case report forms monitored by the Pediatric Clinical Trial Office of the G. Gaslini hospital.

\section{Statistics}

The study complied with the Consolidated Standards of Reporting Trials (CONSORT) statement and used the intention-to-treat population for analysis [8-10].

Ketprofen lysine salt was used in open conditions as the positive control. Thus, comparisons between the group treated in open label and double blinded groups were descriptive in nature and no formal statistical comparison were performed with ketoprofen lysine salt [11].

Descriptive statistics were reported in terms of means and standard deviation (SD) or with 95\% confidence intervals $(95 \% \mathrm{CI})$ for quantitative variables and in terms of absolute frequencies and percentages for qualitative variables.

The following efficacy parameters were evaluated: Pain Intensity Difference (PID) calculated at each time by subtracting the baseline (CSTP and STPI) pain intensity score from the actual pain intensity score, Sum of Pain Intensity Differences (SPID) and Total Pain Relief (TOTPAR) estimated as the Area Under the Curve (AUC).

The analysis of variance was used to evaluate SPID and TOTPAR comparing paracetamol to placebo. SPID of CSTP Intensity scale was the primary study endpoint. All efficacy evaluations were analyzed by the CochranMantel-Haenszel test comparing paracetamol to placebo. All the tests were two sided and a p value $<0.05$ was considered statistically significant.

The sample size calculation was based on the results reported in a study comparing ibuprofen suspension (10 $\mathrm{mg} / \mathrm{kg})$ and paracetamol $(15 \mathrm{mg} / \mathrm{kg})$ to placebo in children with sore throat [6]. Sixty patients (30 patients per group) were adequate to detect a difference between paracetamol and placebo of 59 in SPID of CSTP Intensity scale, assuming a standard deviation of 88.8 , using a two group t-test with a 0.05 one-sided significance level, and a power higher than $80 \%$. A group of 30 patients treated with ketoprofen lysine salt was included in the trial as active control.

\section{Results}

\section{Patient Enrollment and Baseline characteristics}

Ninety-seven Caucasian school children (55 males and 42 females) with pharyngotonsillitis were recruited. Thirty-two were assigned to paracetamol, 32 to placebo, and 33 to ketoprofen lysine salt (Figure 1). Two patients, initially randomized in the placebo and ketoprofen group, had a subsequent episode of pharyngotonsillitis, were both randomly re-allocated in the paracetamol group but were excluded from the analysis.

Table 1 shows the demographic characteristics and mean baseline (SD) scores assessing the severity of pharyngotonsillitis and pain..

\section{Efficacy and safety evaluation over time of paracetamol versus placebo}

Figure 2 shows the results of primary outcome of the study, the time course of pain in each treatment group, as assessed by children with the CSTP. Paracetamol was significantly more effective than placebo in the SPID of children (two tailed 95\%CI paracetamol-placebo, from -151.3 to $-15.3, \mathrm{p}=0.0171)$. Similar results for the comparison paracetamol versus placebo were obtained when pain was assessed by children with of TOTPAR of the five-faces of the CSTRS ( $\mathrm{p}=0.0039$ ). 
Table 1 Children disposition and demographics at baseline.

\begin{tabular}{lcccc}
\hline & paracetamol $(\mathbf{n}=\mathbf{3 2})$ & placebo $(\mathbf{n}=\mathbf{3 2})$ & ketoprofen $(\mathbf{n}=\mathbf{3 3})$ & total $(\mathbf{n}=\mathbf{9 7})$ \\
\hline Males $\mathrm{n}(\%)$ & $20(62.5 \%)$ & $17(53.1 \%)$ & $18(54.5 \%)$ & $55(56.7 \%)$ \\
Positive Strep-test (\%) & $16(50.0)$ & $15(46.9)$ & $15(45.4)$ & mean (SD) \\
& mean (SD) & mean (SD) & mean (SD) \\
Age (years) & $8.6(1.9)$ & $8.1(1.7)$ & $8.3(1.9)$ & $8.3(1.8)$ \\
Height (cm) & $133.8(11.3)$ & $132.7(11.4)$ & $133.3(12.4)$ & $133.3(11.6)$ \\
Weight (kg) & $30.7(8.5)$ & $30.0(8.0)$ & $33.9(13.1)$ & $31.6(10.2)$ \\
TPS (0-21 points) & $10.9(2.1)$ & $11.4(2.8)$ & $10.6(2.9)$ & $11.0(2.6)$ \\
Temperature ( $\left.{ }^{\circ} \mathrm{C}\right)$ & $37.7(0.7)$ & $37.9(0.9)$ & $38.0(0.8)$ & $37.8(0.8)$ \\
CSTPI (0-200 mm VAS) & $157.4(17.3)^{\mathrm{a}}$ & $158.2(20.2)$ & $158.2(17.1)^{\mathrm{b}}$ & $157.9(18.1)^{\mathrm{c}}$ \\
STPI-parents (0-100 mm VAS) & $63.3(9.9)$ & $63.9(13.9)$ & $64.1(10.2)$ & $63.8(11.3)$ \\
STPI-investigators (0-100 mm VAS) & $67.3(11.5)$ & $68.9(14.4)$ & $69.7(12.1)$ & $68.6(12.6)$ \\
\hline
\end{tabular}

CSTPI = Children's Sore Throat Pain Intensity; STPI = Sore Throat Pain Intensity; TPS = Tonsillo-Pharyngitis Score

a) $\mathrm{n}=31$; b) $\mathrm{n}=32$; c) $\mathrm{n}=95$

Figure 3 shows the time course of pain in each treatment as reported by the SPID as measured by the STPI of parents (panel A) and investigators (panel B), respectively. Paracetamol was significantly more effective than placebo in the SPID of parents $(\mathrm{p}=0.0008)$, while no differences between paracetamol and placebo were detected in the SPID reported by investigators.

Table 2 shows the overall categorical efficacy evaluation by children, parents and investigators at different time points. After 1 hour from dosing, a statistically significant advantages of paracetamol over placebo were detected in the judgement reported by children, parents and investigators. These results were confirmed in the at home assessment performed by children and parents, 4 hours from dosing and after 4-days.

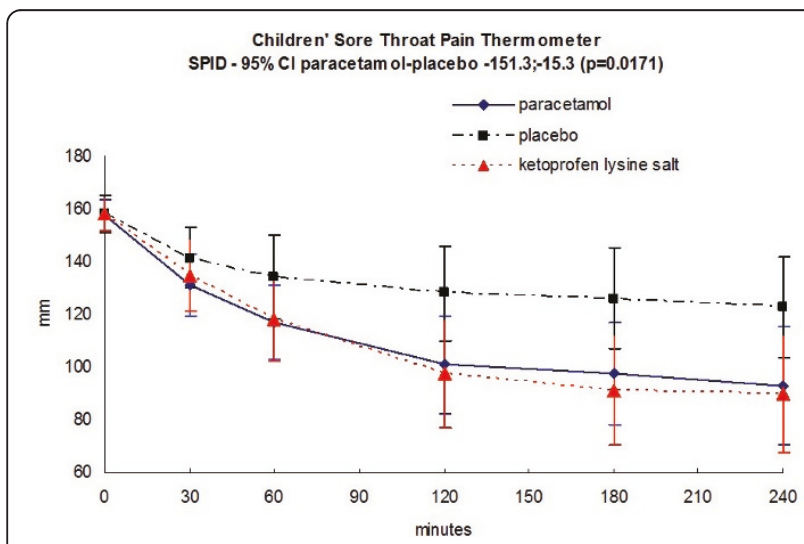

Figure 2 Mean $(95 \% \mathrm{Cl})$ change over time course of pain as assessed by children with the Children's Sore Throat Pain (CSTP) Thermometer with values going from $0 \mathrm{~mm}$ (no pain) to $\mathbf{2 0 0} \mathbf{~ m m}$ (very severe pain). $P$ values refers to the as Sum of Pain Intensity Differences (SPID) with $95 \% \mathrm{Cl}$ for the comparison paracetamol versus placebo.
Efficacy evaluation over time of ketoprofen lysine salt The efficacy of open-label ketoprofen-treated patients group, was similar to paracetamol, and definitely different from placebo (Figure 2, 3 and Table 2).

\section{Safety evaluations}

Safety evaluations at 1, 4 hours after administration was rated good or very good by parents, investigators and children in more than $90 \%$ of the cases for both paracetamol and placebo. No serious adverse events occurred. Four adverse events were observed in 4 patients: bronchitis and rash in the ketoprofen lysine salt group, diarrhoea and cough in the placebo group; none of the event were related to the administered drugs or placebo.

\section{Blinding}

No patients or physicians were unblinded to the paracetamol or placebo treatment.

\section{Discussion}

In this randomised double blind trial children treated with paracetamol showed greater improvement in pain over time with respect to placebo-treated subjects, with similar effects observed in the open label ketoprofentreated group.

In the past, the use of analgesics in the pediatric field was not fully adequate especially because parents were often under the misapprehension that analgesic drugs could have been harmful $[12,13]$. Pain is a part of life and effective analgesia in relation to the intensity of suffering should be provided either in the hospital setting, ambulatory care and home. The assessment and treatment of pain are meaningful parts of pediatric practice and analgesic drugs have been effectively used so far in neonates, infants and children [1,2]. However, the lack of adequate drug pediatric labeling and clinical trials in children called both the Food and Drug Administration 


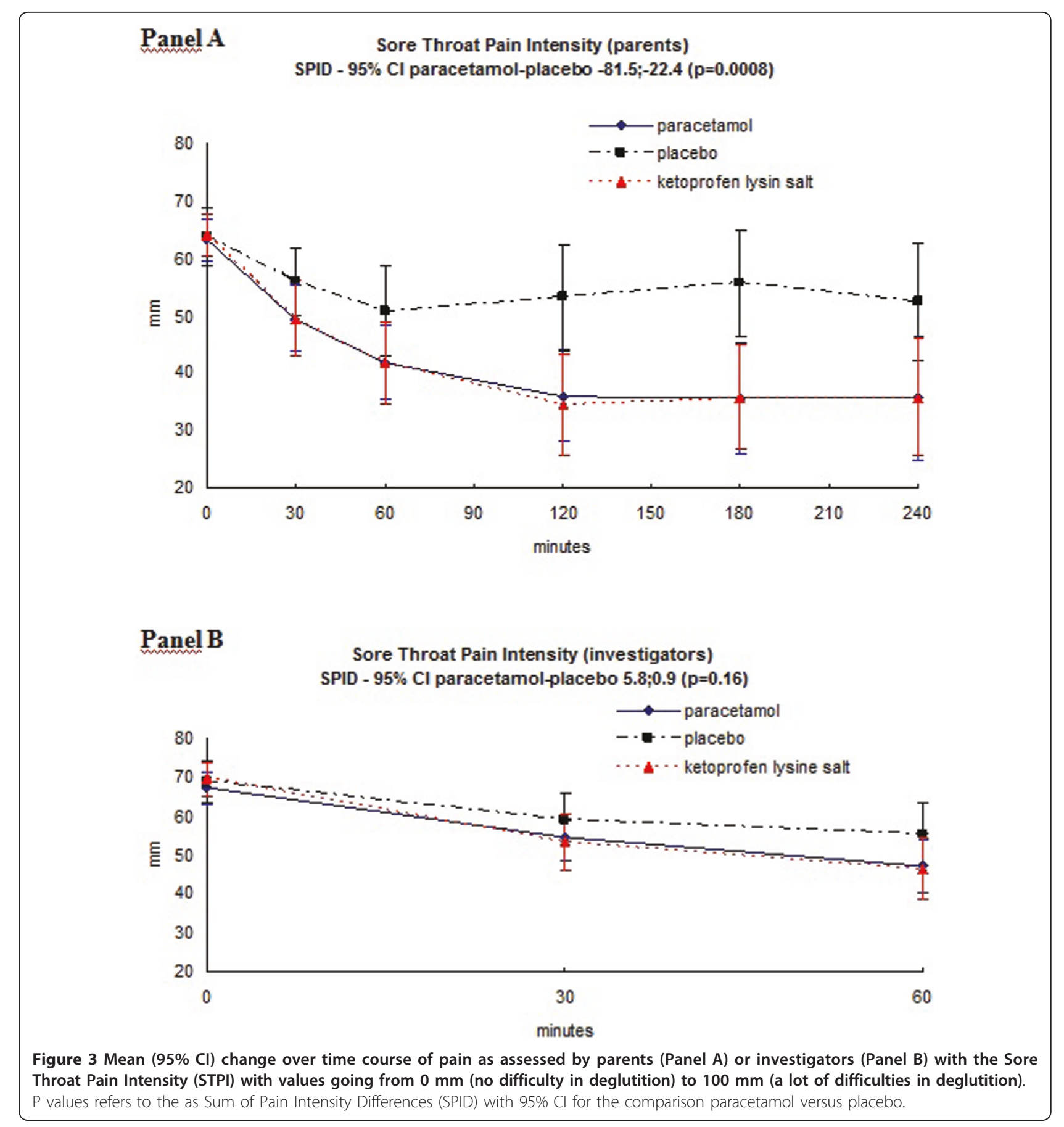

(FDA) and the European Medicines Agency (EMA) for a legislative intervention with the aims to facilitate studies in children [14-16] and establish pediatric network [17-19]. This framework helped to facilitate the conduct this trial in the ambulatory care setting thanks to the Italian national wide net of family pediatrician.

In this double-blind, placebo-controlled clinical trial a 12 $\mathrm{mg} / \mathrm{Kg}$ dosage of paracetamol in syrup was tested in children suffering of sore throat due to pharyngotonsillitis, and using as active control ketoprofen lysine salt administered in an open fashion. The after treatment analgesic effect was independently assessed by the investigator for 1 hour, and by child and parent for 4 hours using validated tools for the assessment of pain relief $[6,20]$. Both active drugs (paracetamol and ketoprofen lysine salt) were more effective than placebo in reducing sore throat, as reported 
Table 2 Efficacy evaluation by children ( 3 levels categorical scale: a lot, little or none), parent and investigator (5 levels categorical scale: very good, good, fair, poor or very poor).

\begin{tabular}{lcccc}
\hline & paracetamol $(\mathbf{n}=\mathbf{3 2})$ & $\begin{array}{l}\text { placebo } \\
(\mathbf{n}=\mathbf{3 2})\end{array}$ & p values & ketoprofen (n = 33) \\
\hline Children (a lot after 1 hour) & $14(44 \%)$ & $7(22 \%)$ & $\mathrm{p} 0.0156$ & $18(55 \%)$ \\
Children (a lot after 4 hours) & $19(59 \%)$ & $5(16 \%)$ & $\mathrm{p} 0.0003$ & $18(55 \%)$ \\
Parent (very good/good at 1 hour) & $19(59 \%)$ & $8(25 \%)$ & $\mathrm{p} 0.0016$ & $20(61 \%)$ \\
Parent (very good/good at 4 hours) & $20(63 \%)$ & $6(19 \%)$ & $\mathrm{p} 0.0001$ & $24(73 \%)$ \\
Investigator (very good/good at 1 hour) & $15(47 \%)$ & $8(25 \%)$ & $\mathrm{p}<0.0316$ & $20(61 \%)$ \\
Investigator (very good/good at Day 4) & $22(69 \%)$ & $20(63 \%)$ & - & $27(82 \%)$ \\
\hline
\end{tabular}

$P$ values refer to the comparison between paracetamol and placebo.

by children and parents while no statistically significant differences between paracetamol and placebo were detected by investigators. This discrepancy may be related to the shorter period of the investigators' observation (1 hour only against the 4 hours of children and parents) and to the known discrepancy in physicians versus parents/ children assessment [21-23]. Neverthless, when analgesic efficacy was evaluated using categorical scales, a statistically significant effect of paracetamol over placebo was detected by children, parents and investigators. The analgesic effect of ketoprofen was similar to that observed with paracetamol. Tolerability of both drug was very good with only four minor adverse events were reported, 2 in the ketoprofen group and 2 in the placebo group.

The analgesic efficacy of paracetamol in the treatment of pain in children is widely recognized, even if few consistent experiences are available in literature. Schachtel et al rated ibuprofen and acetaminophen (at $15 \mathrm{mg} / \mathrm{kg}$ ) as significantly effective compared with placebo $(\mathrm{p}<$ 0.05 ) in children with acute sore throat under doubleblind, placebo-controlled conditions [6]. Bertin et al found that ibuprofen but not paracetamol (at $10 \mathrm{mg} / \mathrm{kg}$ ) was superior to placebo on day 2 for pain control in a double blind placebo-controlled trial in children with otitis media [24] or pharyngitis [25]. Hamalainen et al [26] found that ibuprofen was twice as likely as acetaminophen to abort migraine within 2 hours versus placebo in their double blind trial. The meta-analysis by Perrott et al [27] showed that in children, single doses of ibuprofen $(4-10 \mathrm{mg} / \mathrm{kg})$ and acetaminophen $(7-15 \mathrm{mg} / \mathrm{kg})$ have similar efficacy for relieving moderate to severe pain, and similar safety as analgesics or antipyretics. More recently, Clark et al in a trial with a partial blinded randomisation, found that ibuprofen was superior to paracetamol, or codein for acute pain relief in children with musculoskeletal trauma referred to a paediatric emergency department [13].

\section{Conclusions}

In conclusion, this study confirm that a single oral dose of paracetamol or ketoprofen lysine salt are safe and effective analgesic treatments for children with sore throat in daily pediatric ambulatory care.

\section{Acknowledgements}

We thank Drs Anna Tortorelli, Simona Angioloni, Luca Villa and Mr Michele Pesce for the overall management and monitoring of the trial.

The Study was supported entirely by ACRAF Italy S.p.A.

\section{Author details}

'IRCCS G Gaslini, Pediatria II, Reumatologia, PRINTO, Genoa, Italy. ${ }^{2}$ Local Health Unit (Azienda Sanitaria Locale -ASL) 3 "Genovese", Genoa, Italy. ${ }^{3}$ RCCS G Gaslini, Scientific Direction, Clinical Pharmacology and Pediatric Clinical Trials Office, Genoa, Italy. ${ }^{4}$ Headquarters Medical Department, ACRAF S.p.A, Rome, Italy. ${ }^{5}$ RCCS G. Gaslini, Pediatria II, Reumatologia and Dipartimento di Pediatria, Università degli Studi di Genova, Genoa, Italy.

\section{Authors' contributions}

NR, ODCA and AM had a pivotal role in study design (including protocol and case report form development), data collection (including local monitoring but excluding enrollment of individual patients), data analysis, data interpretation through the critical revision of the company study report. The very preliminary draft of the paper was written internally by the company and deeply revised by NR, ODCA and AM. Company had the right to revise the version to be submitted but the final decision about paper submission relied entirely on NR, ODCA and AM.

$L C, R J, F F, G P, M Z$, enrolled patients into the study and revised critically the paper version to be submitted.

All authors have read and agreed to its content, and that any experimental research that is reported in the manuscript has been performed with the approval of an appropriate ethics committee.

\section{Competing interests}

ES, ADV, PD are employees of ACRAF Italy S.p.A.

The IRCCS G. Gaslini (where NR, ODCA and AM are full time employees)and the investigators (LC, RJ, FF, GP, MZ) received a research grant for the conduct of the study.

No grant has been provide for the paper writing.

Received: 13 April 2011 Accepted: 29 September 2011

Published: 29 September 2011

\section{References}

1. Walco GA, Cassidy RC, Schechter NL: Pain, hurt, and harm. The ethics of pain control in infants and children. N Engl J Med 1994, 331(8):541-4.

2. Berde $C B$, Sethna NF: Analgesics for the treatment of pain in children. $N$ Engl J Med 2002, 347(14):1094-103.

3. Astuto M, Rosano G, Rizzo G, Disma N, Di CA: Methodologies for the treatment of acute and chronic nononcologic pain in children. Minerva Anestesiol 2007, 73(9):459-65.

4. Woo WW, Man SY, Lam PK, Rainer TH: Randomized double-blind trial comparing oral paracetamol and oral nonsteroidal antiinflammatory drugs for treating pain after musculoskeletal injury. Ann Emerg Med 2005, 46(4):352-61. 
5. Bertolini A, Ferrari A, Ottani A, Guerzoni S, Tacchi R, Leone S: Paracetamol: new vistas of an old drug. CNS Drug Rev 2006, 12(3-4):250-75.

6. Schachtel BP, Thoden WR: A placebo-controlled model for assaying systemic analgesics in children. Clin Pharmacol Ther 1993, 53(5):593-601.

7. Principi N: [Guidelines for the therapeutic use of NSAIDs in pediatrics]. Minerva Pediatr 1997, 49(9):379-86.

8. Moher D, Schulz KF, Altman DG, for the CONSORT Group, The CONSORT statement: revised recommendations for improving the quality of reports of parallel-group randomised trials. Lancet 2001, 357(9263):1191-4

9. Hopewell S, Clarke M, Moher D, Wager E, Middleton P, Altman DG, et al: CONSORT for reporting randomised trials in journal and conference abstracts. Lancet 2008, 371(9609):281-3.

10. Schulz KF, Altman DG, Moher D, Fergusson D: CONSORT 2010 changes and testing blindness in RCTs. Lancet 2010, 375(9721):1144-6.

11. European Medicine Agency (EMA): ICH Topic E 10. Choice of control group in clinical trials. Note for guidance on choice of control group in clinical trials (CPMP//CH/364/96) 2001, 1-30[http://www.ema.europa.eu/pdfs/ human/ich/036496en.pdf].

12. Spedding RL, Harley D, Dunn FJ, McKinney LA: Who gives pain relief to children? J Accid Emerg Med 1999, 16(4):261-4.

13. Clark E, Plint AC, Correll R, Gaboury I, Passi B: A randomized, controlled trial of acetaminophen, ibuprofen, and codeine for acute pain relief in children with musculoskeletal trauma. Pediatrics 2007, 119(3):460-7.

14. Connor JD: A look at the future of pediatric therapeutics: an investigator's perspective of the new pediatric rule. Pediatrics 1999, 104(3):610-3.

15. Regulation (EC) no $1901 / 2006$ of the European parliament and of the Council of 12 December 2006 on medicinal products for paediatric use and amending Regulation (EEC) No 1768/92, Directive 2001/20/EC Directive 2001/83/EC and Regulation (EC) No 726/2004. Official Journal of the European Union 2006, L 378:1-19.

16. Ruperto N, Martini A, for the Paediatric Rheumatology International Trials Organization (PRINTO): Use of unlabelled and off licence drugs in children. A European paediatric rule is needed to protect children. $B M J$ 2000, 320(7243):1210-1.

17. Caldwell PHY, Murphy SB, Butow PN, Craig JC: Clinical trials in children. Lancet 2004, 364(9436):803-11.

18. Clumeck N, Katlama C: Call for network of Centres of Excellence in clinical research in Europe. Lancet 2004, 363(9412):901-2.

19. The Network of Paediatric Networks at the EMEA Implementing Strategy (Doc. Ref. EMEA/MB/543523/2007). 2008, 1-7[http://www.emea.europa.eu/ pdfs/human/paediatrics/54352307en.pdf].

20. Schachtel BP, Fillingim JM, Thoden WR, Lane AC, Baybutt Rl: Sore throat pain in the evaluation of mild analgesics. Clin Pharmacol Ther 1988, 44(6):704-11.

21. Ravelli A, Viola S, Migliavacca D, Pistorio A, Ruperto N, Martini A: Discordance between proxy-reported and observed assessment of functional ability of children with juvenile idiopathic arthritis. Rheumatology 2001, 40(8):914-9.

22. Yen JC, Abrahamowicz M, Dobkin PL, Clarke AE, Battista RN, Fortin PR: Determinants of discordance between patients and physicians in their assessment of lupus disease activity. J Rheumatol 2003, 30(9):1967-76.

23. Sztajnbok F, Coronel-Martinez DL, az-Maldonado A, Novarini C, Pistorio A, Viola S, et al: Discordance between physician's and parent's global assessments in juvenile idiopathic arthritis. Rheumatology 2006, 46(1):141-5.

24. Bertin L, Pons G, d'Athis P, Duhamel JF, Maudelonde C, Lasfargues G, et al: A randomized, double-blind, multicentre controlled trial of ibuprofen versus acetaminophen and placebo for symptoms of acute otitis media in children. Fundam Clin Pharmacol 1996, 10(4):387-92.

25. Bertin L, Pons G, d'Athis P, Lasfargues G, Maudelonde C, Duhamel JF, et al: Randomized, double-blind, multicenter, controlled trial of ibuprofen versus acetaminophen (paracetamol) and placebo for treatment of symptoms of tonsillitis and pharyngitis in children. J Pediatr 1991, 119(5):811-4

26. Hamalainen ML, Hoppu K, Valkeila E, Santavuori P: Ibuprofen or acetaminophen for the acute treatment of migraine in children: a double-blind, randomized, placebo-controlled, crossover study. Neurology 1997, 48(1):103-7.
27. Perrott DA, Piira T, Goodenough B, Champion GD: Efficacy and safety of acetaminophen vs ibuprofen for treating children's pain or fever-A meta-analysis. Arch Pediatr Adolesc Med 2004, 158(6):521-6.

doi:10.1186/1824-7288-37-48

Cite this article as: Ruperto et al:: A randomized, double-blind, placebocontrolled trial of paracetamol and ketoprofren lysine salt for pain control in children with pharyngotonsillitis cared by family pediatricians. Italian Journal of Pediatrics 2011 37:48.

\section{Submit your next manuscript to BioMed Central and take full advantage of:}

- Convenient online submission

- Thorough peer review

- No space constraints or color figure charges

- Immediate publication on acceptance

- Inclusion in PubMed, CAS, Scopus and Google Scholar

- Research which is freely available for redistribution

Submit your manuscript at www.biomedcentral.com/submit
Ciomed Central 